\title{
Congenital total pulmonary venous return anomaly
}

INSERM

\section{Source}

INSERM. (1999). Orphanet: an online rare disease and orphan drug data base. Congenital total pulmonary venous return anomaly. ORPHA:99125

Total pulmonary venous return (TAPVR) is a form of congenital pulmonary venous return (see this term)where all of the pulmonary veins drain into the right atrium or one of its tributaries, instead of the left atrium, leading to various manifestations such as fatigue, exertional dyspnea, pulmonary arterial hypertension, cyanosis and progressive congestive heart failure. 